\title{
Increased Expression of Matrix Metalloproteinase-1 in Systemic Vessels of Preeclamptic Women
}

\section{A Critical Mediator of Vascular Dysfunction}

\author{
Guadalupe Estrada-Gutierrez, ${ }^{\dagger}$ \\ Renato E. Cappello, ${ }^{*}$ Nikita Mishra, ${ }^{* \ddagger}$ \\ Roberto Romero, ${ }^{89 \|}$ Jerome F. Strauss III, ${ }^{*}$ and \\ Scott W. Walsh*‡ \\ From the Departments of Obstetrics and Gynecology" and \\ Physiology and Biophysics, ${ }^{\neq}$Virginia Commonwealth University \\ Medical Center, Richmond, Virginia; the Department of Perinatal \\ Infectology and Immunology, ${ }^{\dagger}$ Instituto Nacional de \\ Perinatologia, Mexico City, Mexico; the Perinatology Research \\ Branch, ${ }^{\S}$ National Institute of Child Health and Human \\ Development/National Institutes of Health, Department of Health \\ and Human Services, Bethesda, Maryland, and Detroit, \\ Michigan; the Department of Obstetrics and Gynecology, "Wayne \\ State University/Hutzel Hospital, Detroit, Michigan; and the \\ Center for Molecular Medicine and Genetics," Wayne State \\ University, Detroit, Michigan
}

This study was conducted to determine the following: (1) whether matrix metalloproteinase-1 (MMP-1) is increased in systemic vessels of preeclamptic women, (2) whether this increase might be mediated by neutrophils, and (3) whether MMP-1 could be responsible for vascular dysfunction. Omental arteries and plasma were collected from healthy pregnant and preeclamptic women. Omental arteries were evaluated for gene and protein expression of MMP-1, collagen type $1 \alpha$, tissue inhibitor of metalloproteinase-1, and vascular reactivity to MMP-1. Gene and protein expression levels were also evaluated in human vascular smooth muscle cells (VSMCs) co-cultured with activated neutrophils, reactive oxygen species, or tumor necrosis factor $\alpha$. Vessel expression of MMP-1 and circulating MMP-1 levels were increased in preeclamptic women, whereas vascular expression of collagen or tissue inhibitor of metalloproteinase-1 were down-regulated or unchanged. In cultured VSMCs, the imbalance in collagen-regulating genes of preeclamptic vessels was reproduced by treatment with neutrophils, tumor necrosis factor $\alpha$, or reactive oxygen species. Chemotaxis studies with cultured cells revealed that MMP-1 promoted recruitment of neutrophils via vascular smooth muscle release of interleukin-8. Furthermore, MMP-1 induced vasoconstriction via protease-activated receptor-1, whose expression was significantly increased in omental arteries of preeclamptic women and in VSMCs co-cultured with neutrophils. Collectively, these findings disclose a novel role for MMP-1 as a mediator of vasoconstriction and vascular dysfunction in preeclampsia. (Am J Pathol 2011, 178:451-460; DOI: 10.1016/j.ajpath.2010.11.003)

Preeclampsia is defined as new-onset hypertension with proteinuria during pregnancy. ${ }^{1,2}$ Pathological edema is a frequent complication. Hypertension is associated with extensive vascular remodeling characterized by rearrangement of extracellular matrix proteins $^{3-5}$; however, how this process occurs is not fully understood.

Recently, neutrophil infiltration of the systemic vasculature was demonstrated in preeclamptic women. ${ }^{6-8}$ Infiltration requires activation of the neutrophils, which most likely occurs as they circulate through the intervillous space and are exposed to increased levels of oxidized lipids secreted by the placenta. 9,10 Neutrophils produce inflammatory mediators, such as reactive oxygen species (ROS) and tumor necrosis factor (TNF) $\alpha,{ }^{11,12}$ which induce vascular expression of extracellular matrix proteins, particularly matrix metalloproteinases (MMPs). ${ }^{13-16} \mathrm{Be}-$ yond their matrix remodeling properties, MMPs are

Supported in part by Fogarty grant 1D43 TW007692 (G.E.-G.); the National Center on Minority Health and Health Disparities grant P60 MD002256 (J.F.S.); the Perinatology Research Branch, Division of Intramural Research, Eunice Kennedy Shriver National Institute of Child Health and Human Development, National Institutes of Health, Department of Health and Human Services grant N01 HD-2-3342 (J.F.S.); and the National Heart, Lung, and Blood Institute grant R01 HL069851 (S.W.W.).

Accepted for publication September 28, 2010.

Supplemental material for this article can be found at http://ajp. amjpathol.org or at doi:10.1016/j.ajpath.2010.11.003.

Address reprint requests to Scott W. Walsh, Ph.D., Department of Obstetrics and Gynecology, Virginia Commonwealth University, PO Box 980034, Richmond, VA 23298-0034. E-mail: swwalsh@vcu.edu. 
involved in short-term biological processes, including regulation of vascular reactivity and leukocyte activation. ${ }^{17-21}$ Interestingly, these biological processes are altered in women with preeclampsia. ${ }^{1,22,23}$

These observations led us to hypothesize that neutrophil infiltration could affect vascular expression of MMPs and other extracellular matrix proteins, resulting in vascular dysfunction in women with preeclampsia. By using blood vessels from omental fat, we found that MMP-1 is increased in the vasculature of women with preeclampsia compared with those experiencing a healthy pregnancy. Omental fat vessels were studied because they are representative of systemic blood vessels and they contribute to total peripheral vascular resistance. Herein, we also demonstrate that neutrophils induce secretion of MMP-1 by human vascular smooth muscle cells (VSMCs) in vitro. Furthermore, we identified that, in addition to collagen degradation, active MMP-1 induces chemotaxis of neutrophils through release of interleukin (IL)-8 by VSMCs and MMP-1 causes vasoconstriction via protease-activated receptor-1 (PAR-1). Taken together, our findings suggest a novel mechanism leading to clinical manifestations of preeclampsia, consisting of increased vascular expression of MMP-1 mediated by neutrophil infiltration.

\section{Materials and Methods}

\section{Study Subjects}

Omental fat biopsy specimens were obtained from preeclamptic and healthy pregnant women at the time of cesarean section. Preeclamptic patients had blood pressures of $140 / 90 \mathrm{mmHg}$ or higher on two separate readings 6 hours apart and proteinuria ( $0.3 \mathrm{~g}$ protein/24 hours or one plus urine dipstick result). Placentas for the isolation of VSMCs and blood samples for neutrophil isolation were obtained from healthy pregnant women at term deliveries. Blood samples from healthy pregnant and preeclamptic women for MMP-1 measurement were obtained during the third trimester. Informed consent was obtained before surgery. The Office of Research Subjects Protection, Virginia Commonwealth University, Richmond, approved this study.

\section{VSMC Culture and Treatment}

Human VSMCs were isolated from placental chorionic plate arteries of healthy pregnant patients, as previously described. ${ }^{24}$ The cells were treated for 24 hours with ROS generated by the oxidation of $0.05-\mathrm{mmol} / \mathrm{L}$ hypoxanthine (Sigma, St Louis, MO), 0.003- $\mathrm{U} / \mathrm{ml}$ xanthine oxidase (Calbiochem, La Jolla, CA), 1-ng/ml TNF- $\alpha$ (R\&D Systems, Minneapolis, MN), or neutrophils activated with 50$\mu \mathrm{mol} / \mathrm{L}$ arachidonic acid (Cayman Chemical, Ann Arbor, $\mathrm{MI}$ ) in a 1:16 ratio of neutrophils/VSMCs. Hypoxanthine plus xanthine oxidase generates superoxide that quickly dismutates to hydrogen peroxide, the physiological signaling molecule. ${ }^{25}$ Arachidonic acid was used to activate the neutrophils because it is elevated in preeclamptic women and stimulates superoxide production by neutrophils. ${ }^{26}$ Activated neutrophils were washed before expo- sure to VSMCs. Conditioned medium was collected and centrifuged for removal of cell debris. Cells were rinsed in PBS and harvested for RNA or protein extraction.

\section{Extracellular Matrix Gene Profiling}

RNA was extracted from homogenized omental arterial blood vessels or VSMCs using the RiboPure kit (Ambion, Austin, TX). Reverse transcription was performed with $0.15-\mu \mathrm{g}$ RNA using a commercially available kit ( $\mathrm{RT}^{2}$ First Strand kit; SABiosciences, Frederick, MD). Gene profiling was generated using an array (Human Extracellular Matrix and Adhesion Molecules $\mathrm{RT}^{2}$ Profiler PCR Array; SABiosciences), and the array was analyzed with a template (RT ${ }^{2}$ Profiler PCR Array Data Analysis Template v3.0; SABiosciences).

\section{Quantitative RT-PCR}

Omental arterial blood vessels and VSMCs were processed for RNA extraction and first-strand cDNA synthesis, as previously described. The expression levels of MMP-1, tissue inhibitor of metalloproteinase-1 (TIMP-1), collagen type $1 \alpha 1$ (COL1A1), and PAR-1 were quantified by real-time RT-PCR using commercial primers (SABiosciences) and a mix (SYBR Green PCR Master Mix; SABiosciences). Data were normalized to the gene for $\beta$-actin (ACTB) by the $\Delta \Delta C$ t method. Initially, a panel of five housekeeping genes was used for the real-time RT-PCR arrays. The results for the housekeeping genes were consistent; therefore, ACTB was chosen for subsequent targeted real-time RT-PCR. Dissociation melting-curve analysis confirmed the specificity of the PCR.

\section{Western Blotting}

Protein lysates from omental arterial vessel segments or VSMCs were homogenized in $0.5 \mathrm{ml}$ of mammalian protein extraction reagent (Pierce, Rockford, IL) containing $\times 1$ Halt protease inhibitor (Thermo Scientific, Pittsburgh, $\mathrm{PA}$ ) and 0.5-mmol/L EDTA (Invitrogen, Carlsbad, CA). Membrane protein extraction for PAR-1 detection was performed with lysis buffer containing 20-mmol/L Tris, 150-nmol/L sodium chloride, and $1 \%$ NP40, with $\times 1$ Halt protease inhibitor. Denatured protein lysates $(50 \mu \mathrm{g})$ were resolved by SDS-polyacrylamide gel electrophoresis and electrotransferred to a membrane (Immobilon-FL; Millipore, Billerica, MA). Blots were probed for $\beta$-actin and MMP-1, TIMP-1, COL1A1, or PAR-1. The source of primary antibodies and dilutions used was as follows: $\beta$-actin (1:1000, Sigma A2066), MMP-1 (0.2 $\mu \mathrm{g} / \mathrm{ml}$, R\&D Systems AF901), TIMP-1 (2 $\mu \mathrm{g} / \mathrm{ml}$, R\&D Systems MAB970), COL1A1 (1:1000, Santa Cruz sc-8784; Santa Cruz Biotechnology, Santa Cruz, CA), or PAR-1 (0.2 $\mu \mathrm{g} / \mathrm{ml}, \mathrm{R} \& \mathrm{D}$ Systems AF3855). The secondary antibodies used included donkey anti-rabbit (Alexa Fluor 680, 1:20,000, Invitrogen A10043) for the detection of $\beta$-actin, in combination with donkey anti-goat (IRDye800, 1:20,000, Rockland 605-731-125; Rockland, Gilbertsville, PA) or goat anti-mouse (IRDye800, 1:20,000, Rockland, 610-132-003) for detection of MMP-1, COL1A1 and 
PAR-1, or TIMP-1, respectively. Immunoreactive proteins were detected and analyzed with an available system (LI-COR Odyssey Infrared Imaging System) using computer software (Odyssey 2.1; Thermo Scientific, Pittsburgh, PA).

\section{Immunohistochemistry}

The MMP-1 was localized in 8- $\mu \mathrm{m}$ omental fat tissue sections using an anti-MMP-1 antibody $(15 \mu \mathrm{g} / \mathrm{ml}$, No. AF901, R\&D Systems). Immunohistochemical staining was performed using a kit (SuperPicture HRP Polymer Conjugate Goat Primary [diaminobenzidine] kit (Zymed, San Francisco, CA) and tissue was counterstained with hematoxylin QS (Vector Laboratories, Burlingame, CA).

\section{Treatment of VSMCs with MMP-1}

Confluent primary cultures of VSMCs were exposed overnight to 0.025-, 0.25-, 2.5-, and 25-ng/ml MMP-1 (Calbiochem) in serum-free 199 media with 1\% sodium pyruvate and 1\% antibiotic-antimycotic (Invitrogen). ProMMP-1 was activated in TTC buffer $(50-\mathrm{mmol} / \mathrm{L}$ Tris- $-\mathrm{HCl}$, $\mathrm{pH}$ 7.5; 1 -mmol/L calcium chloride; and $0.05 \%$ Triton $\mathrm{X}$-100) using 1.0-mmol/L 4-aminophenyl mercuric acetate (Calbiochem). The 4-aminophenyl mercuric acetate was removed by ultrafiltration, as previously recommended. ${ }^{27}$ Changes in the extracellular matrix arrangement were documented by light microscopy. Supernatants were filtered through a $0.2-\mu \mathrm{m}$ membrane (Corning, Corning, NY) and preserved at $-70^{\circ} \mathrm{C}$ until use.

\section{Enzyme-Linked Immunosorbent Assay and Enzyme Immunoassay Analyses}

Commercial enzyme-linked immunosorbent assays were used to quantify total MMP-1 (unactivated proenzyme and active forms), active MMP-1 (GE Health care, Piscataway, NJ), TIMP-1 (GE Health care), and IL-8 (R\&D Systems). Carboxyterminal cross-linked telopeptide of collagen type 1 was measured in concentrated VSMC supernatants using a commercial enzyme immunoassay (Orion Diagnostica, Espoo, Finland).

\section{Chemotaxis Assay}

Supernatants from VSMCs treated with different doses of MMP-1 were tested for neutrophil chemotaxis using single-well Boyden chambers (Neuro Probe, Gaithersburg, MD), as previously described. ${ }^{28}$ Briefly, $500 \mu \mathrm{L}$ of serumfree 199 media containing 50,000 neutrophils was placed on top of the polycarbonate membrane (5- $\mu \mathrm{m}$ pore size; TMTP01300; Millipore, Billerica, MA) with the VSMC supernatant as chemoattractant in the lower compartment. Chambers were incubated for 90 minutes at $37^{\circ} \mathrm{C}$ in humidified air containing $5 \%$ carbon dioxide. The IL-8neutralizing antibody (20 $\mu \mathrm{g} / \mathrm{ml}$, R\&D Systems) was used to determine the importance of IL-8 for neutrophil migration. Media with MMP-1 alone in the lower chamber served as the control. The VSMC supernatants were re- moved and centrifuged at $500 \times g$ for 5 minutes. The pellet was stained with an anti-CD45-fluorescein isothiocyanate antibody (Beckman Coulter, Brea, CA), and the total number of migrating neutrophils was assessed by flow cytometry (FC 500; Beckman Coulter).

\section{Vessel Reactivity Studies}

Omental arteries from healthy pregnant women (diameter, 200 to $500 \mu \mathrm{m}$ ) were dissected in cold Dulbecco's PBS (Invitrogen) containing glucose, sodium pyruvate, calcium chloride, and magnesium chloride. Arteries (1 $\mathrm{cm}$ in length) were mounted on glass microcannulae of a pressure myograph system (model 110P; Danish Myo Technology, Marietta, GA). Vessels were immersed in the myograph chamber containing $10 \mathrm{ml}$ of Dulbecco's PBS maintained at $37^{\circ} \mathrm{C}$. After a period of stabilization, the vessel was challenged with $60-\mathrm{mmol} / \mathrm{L}$ potassium chloride to assess vessel reactivity and charge intracellular calcium stores. Activated MMP-1 was then perfused through the vessel lumen for 10-minute periods at 0.025 , $0.25,2.5$, and $25 \mathrm{ng} / \mathrm{ml}$. Unactivated pro-MMP-1 was perfused at a dose of $2.5 \mathrm{ng} / \mathrm{ml}$ to assess the necessity for enzyme activation. Vessel pressure was maintained at constant inlet $(45 \mathrm{mmHg})$ and outlet $(42 \mathrm{mmHg})$ pressures to achieve flow through the vessel. The MMP-1 treatments were repeated in the presence of $10-\mu \mathrm{mol} / \mathrm{L}$ $\mathrm{SCH}-79797$ (Tocris Bioscience, Ellisville, MO), a PAR-1 antagonist.

\section{Statistical Analysis}

Quantitative results are presented as mean \pm SEM. We compared parameters between two groups by the Student's $t$ test. We also compared parameters for more than two groups by one-way analysis of variance with Dunn's posttest or two-way analysis of variance with the Bonferroni posttest, as appropriate. $P<0.05$ was considered statistically significant.

\section{Results}

\section{Study Subject Characteristics}

The clinical data for healthy pregnant subjects and preeclamptic patients were as follows: maternal age (22.8 \pm 4.2 versus $21.2 \pm 2.6$ years; $P=0.49$ ), systolic blood pressure $(124.6 \pm 5.0$ versus $150.8 \pm 2.2 \mathrm{mmHg} ; P<$ $0.0001)$, diastolic blood pressure $(72.6 \pm 6.3$ versus 92.4 $\pm 1.5 \mathrm{mmHg} ; P<0.0001)$, gestational age $(38.5 \pm 0.8$ versus $37.9 \pm 0.8$ weeks; $P=0.28)$, and birth weight (3234 \pm 360 versus $3372 \pm 549 \mathrm{~g} ; P=0.65)$.

\section{MMP-1 Is Increased in the Vasculature of Women with Preeclampsia}

To test the hypothesis that neutrophil infiltration could affect the expression of collagen-regulating genes in the vasculature of women with preeclampsia, we evaluated the expression profile of genes related to extra- 
A

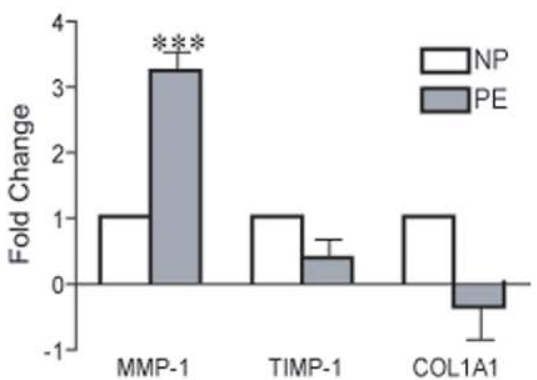

C
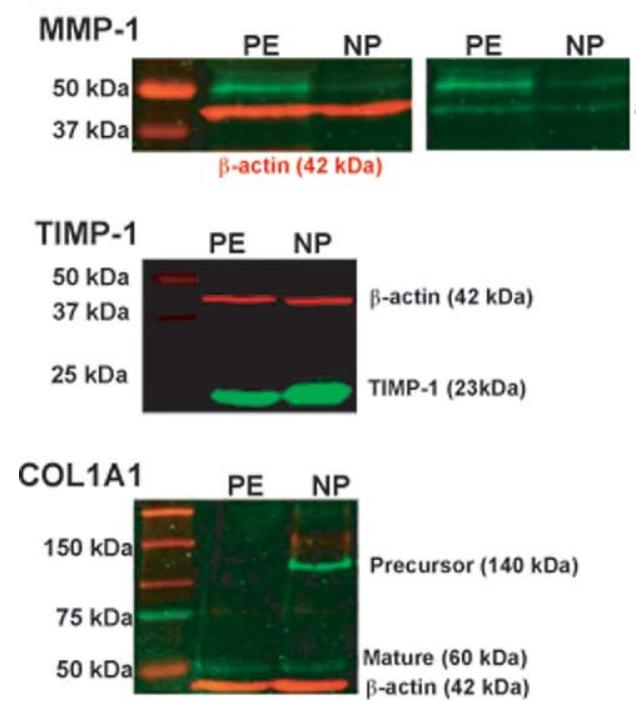

proMMP-1 $(52 \mathrm{kDa})$ active MMP-1 (43 kDa)

B

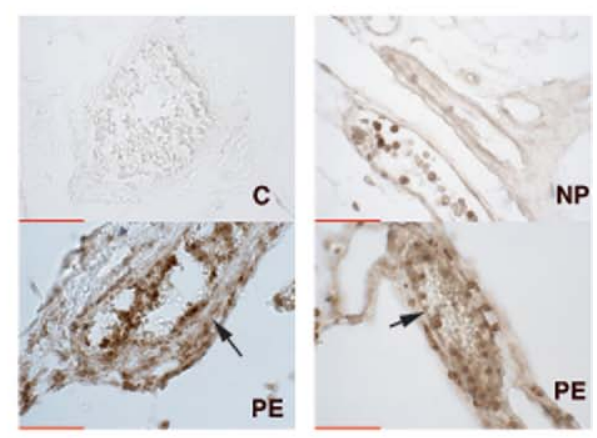

D

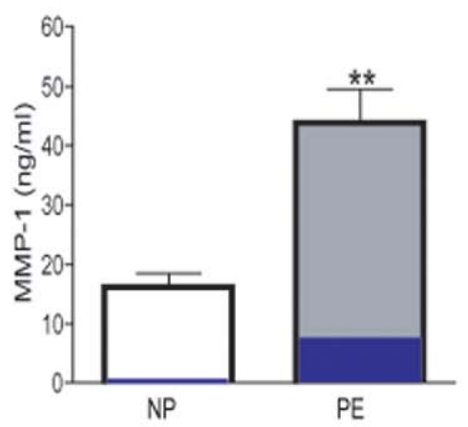

Figure 1. The level of MMP-1 is increased in the vasculature of preeclamptic women versus healthy pregnant women. A: Fold change in gene expression for $M M P 1, T I M P 1$, and $C O L 1 A 1$ in arteries dissected from omental fat from women with preeclampsia (PE) versus a healthy pregnancy (NP). Results are expressed as relative increases or decreases versus controls. Data are given as mean $\pm \operatorname{SEM}(n=6$ different women per group). ${ }^{* * * *} P<0.001$ for PE versus NP. B: Representative MMP-1 immunostaining of blood vessels in omental fat from women with an NP and those with PE. The large arrow on the left PE panel indicates smooth muscle cell staining; and small arrow on right $\mathrm{PE}$ panel, endothelial cell staining. Scale bars $=50 \mu \mathrm{m}$. C: Representative Western blots to assess the presence of MMP-1, TIMP-1, and COL1A1 in lysates of arteries dissected out of omental fat. D: Circulating levels of MMP- 1 in healthy $(n=5)$ and preeclamptic $(n=6)$ women. ${ }^{* * *} P<0.01$ for $\mathrm{PE}$ versus an NP. Percentage of active enzyme is shown in blue ( $2 \%$ for NP and $17 \%$ for PE). Dat are given as mean \pm SEM. C indicates IgG negative control staining of a preeclamptic patient. cellular matrix in omental fat arteries from a healthy pregnant patient and a preeclamptic patient using real-time RT-PCR arrays. The entire list of 84 genes examined can be found in the Supplemental Table S1 (at http://ajp.amjpathol.org). The MMP1 gene (sevenfold increase) was among the eight genes exhibiting a twofold or greater change in expression for a blood vessel from a preeclamptic patient versus a healthy pregnant patient. Four genes were down-regulated, including TIMP1 (twofold decrease) and COL1A1 (almost threefold decrease), which encode the inhibitor and substrate for MMP-1, respectively. Changes in the expression of these three genes were confirmed in omental fat arteries from six preeclamptic and six healthy pregnancies by real-time RT-PCR (Figure 1A). By using omental fat from women with a healthy pregnancy and preeclampsia, we found that preeclamptic women showed substantially greater immunostaining for MMP-1 in their blood vessels than healthy pregnant women. Increased staining for MMP-1 was evident in the endothelium, vascular smooth muscle, and infiltrating leukocytes (Figure 1B), which most likely were neutrophils because they produce MMP- $1^{29}$ and are the most abundant leukocyte that infiltrates the vasculature of preeclamptic women. ${ }^{8}$ Next, we studied MMP-1, TIMP-1, and COL1A1 content in these blood vessels by Western blot analysis. Consistent with gene expression profiles, basal pro-MMP-1, which was negligible in the blood vessels of women with healthy pregnancies, was much higher in samples from women with preeclampsia. In addition, active MMP-1 was more abundant in the vessels of preeclamptic women. The amount of TIMP-1 and mature COL1A1 in the blood vessels from preeclamptic women was not markedly affected; however, the precursor form of COL1A1 was absent from blood vessels of preeclamptic women, indicating that the synthesis of COL1A1 was reduced (Figure 1C). Matrix metalloproteinase- 1 is a secreted protein; therefore, increased vascular expression of MMP-1 should be reflected in the plasma. The mean plasma concentration of MMP-1 measured by enzyme-linked immunosorbent assays was threefold higher in women with preeclampsia than in women with a healthy pregnancy $(P=0.003)$. The activity assay for MMP-1 showed that there was more active MMP-1 circulating in preeclamptic women than in healthy pregnant women (17\% versus $2 \%$ ) (Figure 1D). Taken together, these data suggest that the increase in MMP-1 could cause vascular dysfunction in preeclamptic women by creating an imbalance between collagen synthesis and collagen breakdown, favoring breakdown. These alterations in the vascular collagen type 1 network may be responsible for the edema and protein leakage observed in women with preeclampsia. 
A
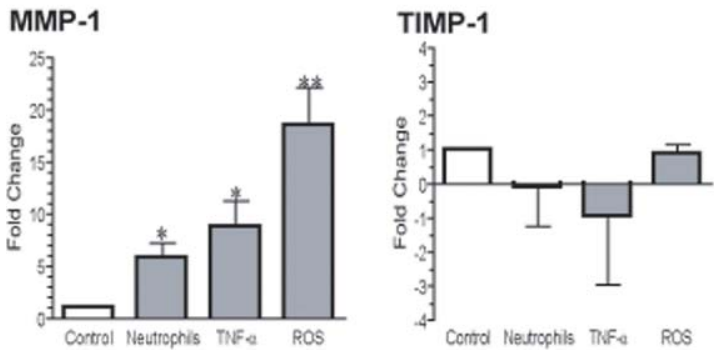

B

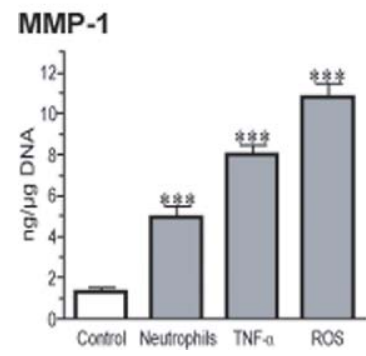

TIMP-1

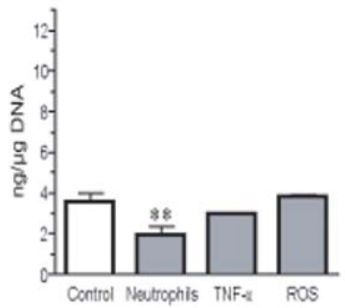

COL1A1

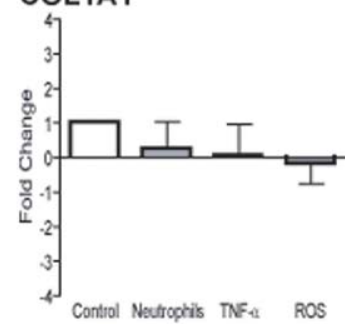

C

COL1A1

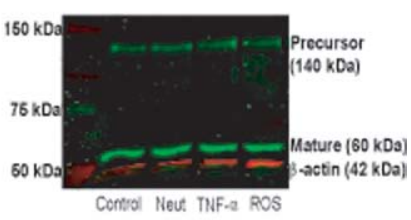

Figure 2. Increased expression and secretion of MMP-1 in VSMCs treated with neutrophils, TNF- $\alpha$, or ROS. A: Fold change in gene expression assessed for MMP1, TIMP1, and COL1A1 in VSMCs treated overnight with neutrophils activated with $50-\mu \mathrm{mol} / \mathrm{L}$ arachidonic acid (1:16 ratio of neutrophils/VSMCs), $1-\mathrm{ng} / \mathrm{ml} \mathrm{TNF-} \alpha$, or ROS $(0.05-\mathrm{mmol} / \mathrm{L}$ hypoxanthine plus $0.003-$ $\mathrm{U} / \mathrm{ml}$ xanthine oxidase). Results are expressed as relative increases or decreases versus controls. Data are given as mean \pm SEM of three experiments in duplicate, representing cell lines from three different women with healthy pregnancies. ${ }^{*} P<0.05$ and ${ }^{* *} P=0.01$ for treated versus control cells. B: Levels of MMP-1 and TIMP-1 in the VSMC culture supernatants after treatments. Data are given as mean \pm SEM of three experiments in duplicate, representing cell lines from three different women with healthy pregnancies. ${ }^{* *} P=0.008$ and ${ }^{* * * *} P<0.001$ for treated versus control cells. C: Representative Western blot showing precursor and mature forms of COL1A1 in VSMC lysates after treatments.
Neutrophils, TNF- $\alpha$, and ROS Increase

\section{Expression and Secretion of MMP-1 by VSMCs}

We propose that neutrophil infiltration into the blood vessels of women with preeclampsia contributes to the changes observed in vascular collagen-regulating gene expression and, in particular, induces the increase in MMP-1. To test this hypothesis, we examined the effects of neutrophils and their soluble products (ie, TNF- $\alpha$ and ROS) on extracellular matrix protein gene expression using primary cultures of human VSMCs, an in vitro model previously validated. ${ }^{24}$ Analysis of the extracellular matrix gene array of VSMCs after overnight treatments showed a similar expression profile as that observed in blood vessels from preeclamptic women (see Supplemental Tables S2-S4 at http://ajp.amjpathol.org), including the upregulation of $M M P 1$ and the down-regulation or no change of TIMP1 and COL1A1 gene expression. Realtime RT-PCR confirmed that neutrophils, TNF- $\alpha$, and ROS significantly up-regulated MMP-1 expression in VSMCs by 6 -fold $(P=0.05)$, 9 -fold $(P=0.028)$, and 19 -fold ( $P$ $=0.001)$, respectively, compared with controls. Although treatments did not significantly affect TIMP1 or COL1A1 gene expression, the trend was for downregulation (Figure $2 \mathrm{~A}$ ). Consistent with gene expression, enzyme-linked immunosorbent assay analysis demonstrated increased concentrations of MMP-1 in VSMC culture supernatants after all three treatments $(P<$ $0.001)$. Treatments decreased or did not affect TIMP-1 secretion (Figure 2B). Western blot analysis of VSMC lysates showed that treatments did not affect COL1A1 in these cells (Figure 2C). Thus, vascular neutrophil infiltration in preeclamptic women and the subsequent production of inflammatory products, such as TNF- $\alpha$ and ROS, could promote the secretion of MMP-1 by VSMCs, favoring modification of the collagen type 1 network in the blood vessels.

\section{MMP-1 Has a Role in the Recruitment of Neutrophils into the Vessel Wall}

Previously, it was demonstrated that neutrophils infiltrate the vasculature of women with preeclampsia ${ }^{6-8}$; therefore, we tested the hypothesis that MMP-1 stimulates VSMCs to produce chemotactic factors, resulting in recruitment of neutrophils into the intimal space, the area between the endothelium and vascular smooth muscle. The VSMC primary cultures were treated overnight with $0.025-, 0.25-, 2.5-$, or $25-\mathrm{ng} / \mathrm{ml}$ active MMP-1; and the cell-free supernatants were tested for chemotaxis using modified Boyden chambers and flow cytometry to determine the number of migrating neutrophils in the lower chamber. Increase in neutrophil migration, as assessed by $\mathrm{CD}_{4} 5^{+}$cell number, was directly proportional to the MMP-1 added to the VSMC culture (Figure 3A). Neutrophil migration was significantly increased by 0.25-, 2.5-, and $25-\mathrm{ng} / \mathrm{ml}$ MMP-1 compared with supernatants of cells treated with MMP- 1 in the presence of IL-8-neutralizing antibody or cells treated with MMP-1 alone $(P<$ $0.001)$. These data indicate that the cells liberated chemotactic factors in response to MMP-1.

To characterize the mechanisms by which the interaction between MMP-1 and VSMC promotes migration of neutrophils, we analyzed the supernatants for IL-8 and C-terminal telopeptide of collagen type 1, a fragment liberated during the degradation of mature collagen type 1 through the action of $\mathrm{MMPs}^{30}$ and a previously described chemoattractant. ${ }^{31,32}$ Interleukin-8 secretion by VSMCs was significantly increased by $0.25-, 2.5-$, and 25-ng/ml MMP-1 $(P<0.01)$ and collagen type 1 fragments by 2.5 - and $25-\mathrm{ng} / \mathrm{ml}$ MMP-1 $(P<0.05$ and $P<$ 0.001 , respectively) compared with control (Figure $3, \mathrm{~B}$ and $\mathrm{C}$ ). Interleukin-8 was primarily responsible for neutrophil migration because migration was significantly inhibited by $82 \%$ to $86 \%$ in the presence of an IL-8- 
A

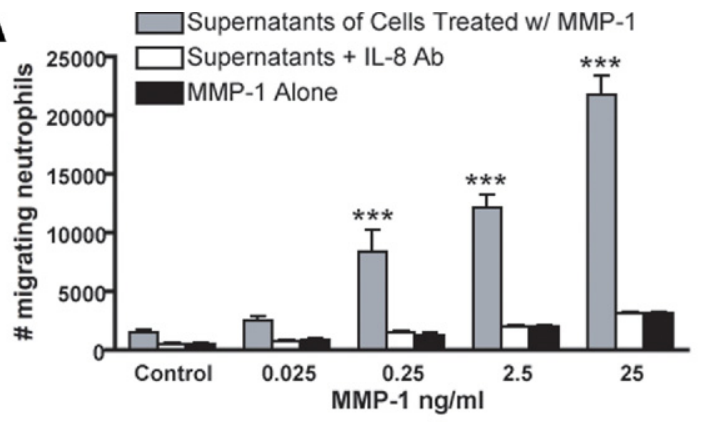

B

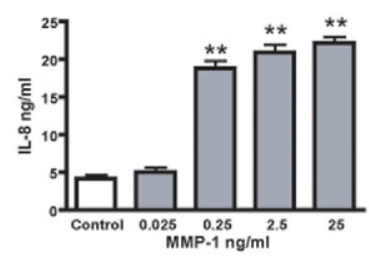

C

\section{D}

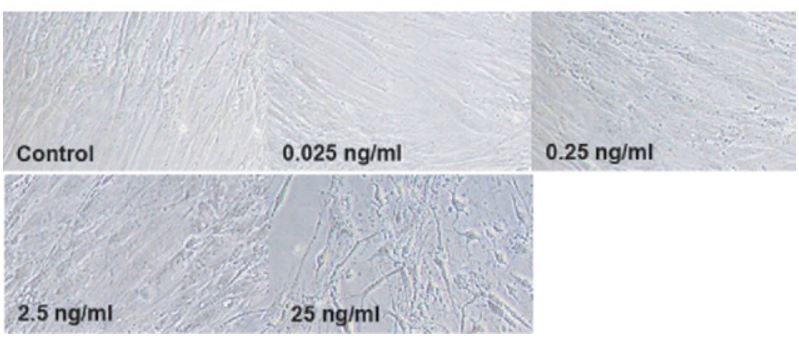

Figure 3. Treatment of VSMCs in vitro with MMP-1 induces chemotactic factors for neutrophils. A: Chemotaxis of neutrophils in response to supernatants of VSMCs treated with different concentrations of active MMP-1, supernatants of VSMCs treated with active MMP-1 in the presence of IL-8neutralizing antibody (IL-8 Ab, $20 \mu \mathrm{g} / \mathrm{ml}$ ), or MMP-1 alone. Data are given as mean \pm SEM of three independent experiments in duplicate. ${ }^{* * *} P<0.001$ versus supernatants with IL-8 Ab or MMP-1 alone. B and C: The IL-8 (B) and C-terminal telopeptide $(\mathbf{C})$ of collagen type 1 in the supernatants of VSMCs after overnight treatment with different concentrations of active MMP-1. Data are given as mean \pm SEM of three independent experiments in duplicate. ${ }^{*} P<0.05,{ }^{* * *} P<0.01$, and ${ }^{* * * *} P<0.001$ versus control supernatants from VSMCs without treatment. D: Representative light microscopy of VSMC culture morphological features after treatment with different concentrations of active MMP-1 (original magnification, $\times 40$ )

neutralizing antibody $(P<0.001)$ (Figure 3A). We speculate that the remaining chemotactic activity was mediated by the degradation fragments of collagen type 1 in the supernatants. Consistent with the collagen type 1 results, MMP-1-treated VSMC cultures observed under light microscopy showed alterations in cell morphological features consistent with a loss of the extracellular matrix arrangement and alterations in cell morphological components in a dose-dependent manner (Figure 3D). These data suggest a key role for MMP-1 in vascular inflammation and neutrophil recruitment to the vessel wall in preeclampsia.

\section{Vascular PAR-1 Is Increased in Preeclampsia}

Beyond structural instability, the increase in MMPs may have additional important effects, such as triggering a variety of signaling pathways that control different cellular responses. ${ }^{18}$ Matrix metalloproteinase- 1 is known to ac- tivate PAR $-1{ }^{33}$ which plays critical roles in coagulation, inflammation, and vascular homeostasis ${ }^{34}$; and its expression is increased in preeclamptic compared with healthy placentas. ${ }^{35}$ We hypothesized that neutrophils infiltrated into the vasculature of women with preeclampsia promote VSMC expression of PAR-1. Thus, we evaluated the potential of neutrophils, TNF- $\alpha$, and ROS to induce expression of PAR-1 in vitro. Treatments with TNF- $\alpha$ and ROS increased expression of PAR1 twice to threefold, as assessed by real-time RT-PCR. However, treatment of VSMCs with neutrophils increased PAR1 expression by approximately eightfold $(P<0.001)$, demonstrating that neutrophils have the potential to transform VSMCs to a phenotype expressing PAR-1 (Figure 4A). Gene expression was confirmed by Western blot analysis (Figure 4B). Furthermore, we found that PAR-1 expression was increased approximately ninefold in omental vessels of women with preeclampsia versus a healthy pregnancy $(P<0.001)$ (Figure $4 C)$, which was confirmed by Western blot (Figure 4D). As can be seen, a major band corresponding to the expected molecular $47-\mathrm{kDa}$ weight of the receptor was detected in VSMCs after all treatments, although the band was more evident when cells were exposed to neutrophils. The same band was present in blood vessels from women with preeclampsia but not from women with healthy pregnancies. Interestingly, an additional lower band emerged in VSMCs treated with neutrophils and in preeclamptic blood vessels (arrows). Because PAR-1 is cleaved to become active, this lower band most probably represents a frag-
A PAR-1

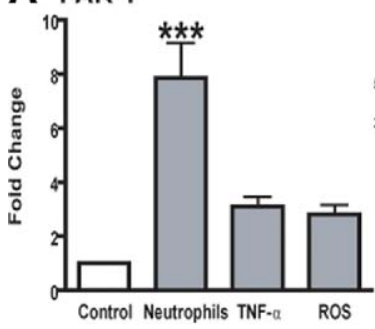

C PAR-1

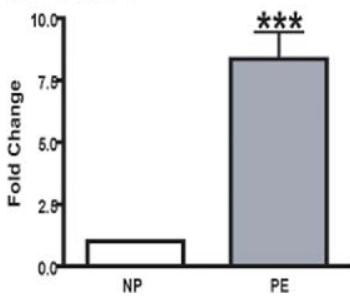

B

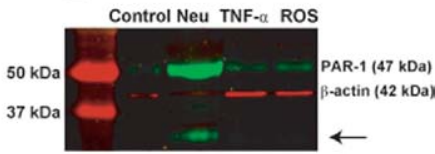

Figure 4. The PAR-1 level is increased in the vasculature during preeclampsia (PE). A: Fold change in PAR-1 expression in VSMCs after overnight treatment with neutrophils activated with $50-\mu \mathrm{mol} / \mathrm{L}$ arachidonic acid (1:16 ratio of neutrophils/VSMCs), $1-\mathrm{ng} / \mathrm{ml}$ TNF- $\alpha$, or ROS $(0.05-\mathrm{mmol} / \mathrm{L}$ hypoxanthine plus $0.003-\mathrm{U} / \mathrm{ml}$ xanthine oxidase). Data are given as mean \pm SEM of three experiments in duplicate, representing cell lines from three different women with healthy pregnancies (NPs). ${ }^{* * * *} P<$ 0.001 for treated versus control cells. B: Representative Western blot for PAR-1 in membrane lysates of VSMCs after treatments. C: PAR-1 expression in blood vessels dissected from omental fat from women with PE versus NP. Data are given as mean \pm SEM ( $n=5$ different women per group). ${ }^{* * * *} P<0.001$ for PE versus NP. D: Representative Western blot for PAR1 in blood vessels from omental fat from women with PE or NP 


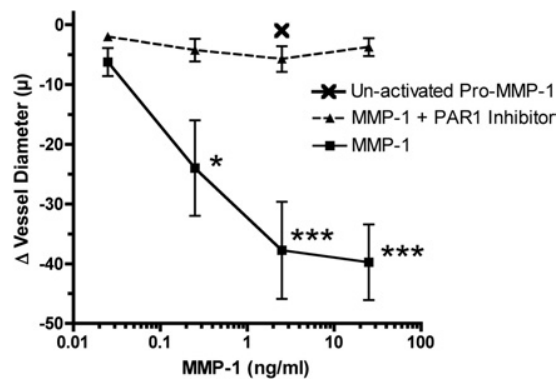

Figure 5. Vasoconstrictor effect of MMP-1 is PAR-1 dependent. The MMP-1 caused dose-dependent vasoconstriction of perfused intact omental arteries obtained from women with healthy pregnancies. The PAR-1 antagonist, SCH-79797 (10 $\mu \mathrm{mol} / \mathrm{L})$, abolished the ability of MMP-1 to cause vasoconstriction. Unactivated pro-MMP-1 was ineffective at a dose of $2.5 \mathrm{ng} / \mathrm{ml}$, which resulted in maximal contraction with active MMP-1; therefore, vasoconstriction was because of enzymatic activity of MMP-1 to activate PAR-1. ${ }^{*} P<0.05$ and ${ }^{* * * *} P<0.001$. Data are given as mean \pm SEM of four separate experiments.

ment of PAR-1, suggesting cleavage and activation of this receptor. Overall, these in vitro and in vivo studies support a model in which infiltrating neutrophils enhance PAR-1 production in vascular smooth muscle, which could be activated by increased levels of MMP-1, providing additional support for the pathogenic role of these inflammatory cells and MMP-1 in preeclampsia.

\section{MMP-1 Induces Vasoconstriction via PAR-1}

It was previously demonstrated that MMP-2 affects vascular function by cleaving vasoactive peptides to generate potent vasoconstrictors. ${ }^{19,20,36}$ To ascertain whether MMP-1 has a role in the regulation of vascular reactivity, active enzyme was perfused into the lumen of intact omental arteries at varying concentrations and tested for vasoconstriction using a myograph system. We found that activated MMP-1 directly caused vessel contraction at $0.25 \mathrm{ng} / \mathrm{ml}(P<0.05), 2.5 \mathrm{ng} / \mathrm{ml}(P<$ $0.001)$, and $25 \mathrm{ng} / \mathrm{ml}(P<0.001)$ (Figure 5$)$. Unactivated pro-MMP-1 had no effect on vessel diameter, demonstrating that the vasoconstriction was because of the enzymatic activity of MMP-1. Because increased vascular expression of PAR-1 has been reported in those with hypertension, ${ }^{37,38}$ we explored the possibility that MMP-1-induced vasoconstriction could be specifically mediated via PAR-1. When MMP-1 dose-response was repeated in the presence of $\mathrm{SCH}-79797$, a potent and selective non-peptide PAR-1 antagonist, ${ }^{39}$ vessel contraction was completely abolished (Figure 5). These data demonstrate that activated MMP-1 has potent vasoconstrictor properties that are PAR-1 dependent. This represents an entirely new mechanism to explain hypertension during preeclampsia.

\section{Discussion}

Our finding that MMP-1 is increased in the vasculature of women with preeclampsia presents a novel mechanism for vascular dysfunction associated with this syndrome. We show herein that the increase in MMP-1 may mediate biological processes in the vasculature that involve vessel remodeling and vasoconstriction (Figure 6).

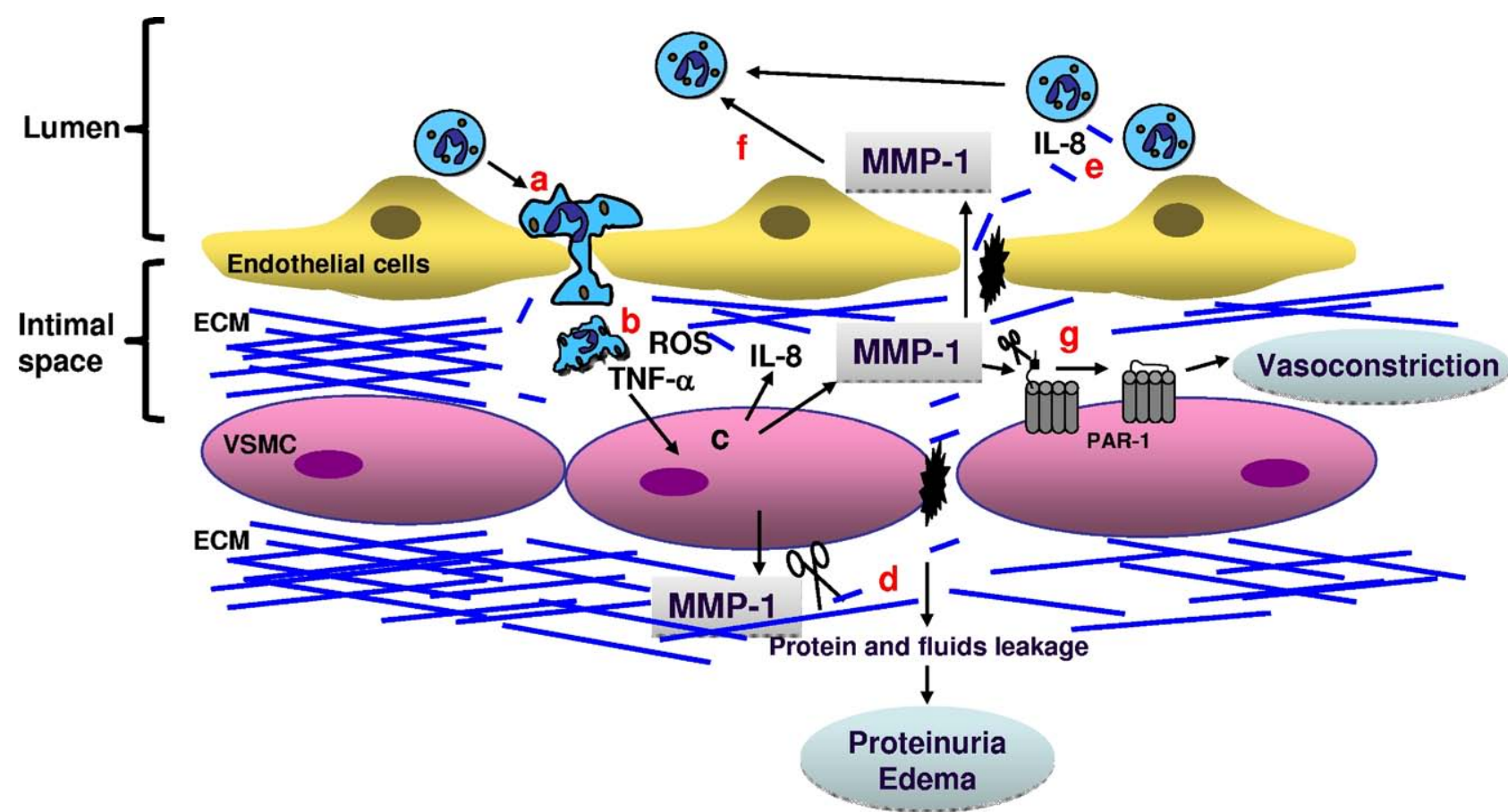

Figure 6. Working model of vascular dysfunction mediated by MMP-1 during preeclampsia. A: Activated neutrophils infiltrate the blood vessels. B: Once in the intimal space, neutrophils secrete TNF- $\alpha$ and ROS. C: This, in turn, stimulates VSMCs to secrete MMP-1 and IL- 8 . D: Increment of MMP-1 induces collagen breakdown, which possibly favors edema and proteinuria. E: The IL-8, and possibly collagen, fragments induce recruitment of more neutrophils, favoring vascular inflammation. F and $\mathbf{G}$ : Active MMP-1 can play additional roles, including enhancement of neutrophil inflammatory response (F) and vasoconstriction through the cleavage of PAR-1 receptor on endothelial cells or VSMCs $(\mathbf{G})$. 
The enhancement in collagenolytic activity suggested by the increase in MMP-1, the lack of increase in TIMP-1, and the lack of precursor form of COL1A1 synthesis during preeclampsia strongly imply the alteration of the collagen network in the blood vessel wall. This is consistent with a previous report ${ }^{40}$ showing that preeclampsia is accompanied by a decrease in collagen type 1 in umbilical cord arteries. Because collagen is found in all three layers of blood vessels and especially around smooth muscle cells of the media, where it provides mechanical strength and maintains the structural integrity of the vasculature, it is reasonable to infer that the damage to this network might increase vascular permeability. Consequently, we propose the hypothesis that leakage of fluids and proteins could result in edema and proteinuria, conditions observed in women with preeclampsia. ${ }^{41,42}$

The maternal vascular system undergoes an inflammatory process during preeclampsia, as evidenced by increased neutrophil activation ${ }^{43-46}$ and vascular neutrophil infiltration. ${ }^{6-8}$ In the early phase of this study, we hypothesized that infiltrating neutrophils could affect expression of genes related to the extracellular matrix. In view of our finding that activated neutrophils induce MMP-1 expression by VSMCs in vitro, we propose that the presence of these inflammatory cells in the preeclamptic blood vessel wall triggers molecular signaling, resulting in an increment of MMP-1 in both vascular tissue (including endothelial and smooth muscle) and circulating blood. This observation agrees with a previous report ${ }^{47}$ that indicates that VSMCs produce MMP-1 after leukocyte contact.

Experimental findings support a role of ROS and TNF- $\alpha$ in the maternal vascular alterations associated with preeclampsia ${ }^{21}$; both are released by activated neutrophils. ${ }^{26,48}$ Evidence presented in this study suggests that the potential mechanism for MMP-1 induction and activation may involve the generation of ROS and TNF- $\alpha$ by infiltrated neutrophils. This notion is supported by studies ${ }^{13,15,16,49}$ showing that TNF- $\alpha$ and ROS modulate the expression of different MMPs in VSMCs and promote the activation of MMPs secreted by VSMCs. The fact that the exposure of VSMC to neutrophils or neutrophil products, such as TNF- $\alpha$ and ROS, resulted in a similar extracellular matrix gene expression pattern as that observed in blood vessels from preeclamptic women provides further evidence for the in vivo role of neutrophils in the vascular remodeling process occurring during preeclampsia

Recently, it was demonstrated that plasma from preeclamptic women stimulates transendothelial migration of neutrophils. ${ }^{50}$ Migration to and local accumulation of leukocytes at the sites of inflammation are critical for the inflammatory response. ${ }^{51}$ Leukocytes need to degrade blood vessel basement membranes to migrate; therefore, proteinases are the most obvious candidates for regulating this step..$^{52} \mathrm{~A}$ previous report ${ }^{53}$ showing novel MMP functions in relation to leukocyte migration and the demonstration that transendothelial migration of leukocytes across high endothelial venules is affected by $\mathrm{MMPs}^{52}$ lead us to speculate that MMP-1 could also be involved in the recruitment of neutro- phils into the vasculature of women with preeclampsia The identification of MMP-1 as a mediator of neutrophil chemotaxis through liberation of IL-8 secretion, and possibly collagen fragments, by VSMCs provides insight into the mechanisms underlying vascular inflammation and, consequently, vascular dysfunction in women with preeclampsia. Although further studies are needed to elucidate the molecular basis of the MMP-1 and neutrophil interaction, we know that the contact between them leads to reciprocal activation in vitro (see Supplemental Figure S1, A and B at http://ajp.amjpathol. org), which indicates bidirectional regulation. Thus, we hypothesize that the increase in MMP-1 is part of a feedforward signaling pathway involving activation and infiltration of neutrophils into the vascular tissue, which is accompanied by secretion of additional amounts of MMP-1 by VSMCs, favoring vascular dysfunction (Figure 6).

The signaling network triggered by neutrophils infiltrated into the vasculature during preeclampsia probably includes the expression of thrombin receptor, PAR-1. As we show herein, VSMCs stimulated in vitro with activated neutrophils, TNF- $\alpha$, or ROS elicit PAR- 1 up-regulation. This $\mathrm{G}$ protein-coupled receptor plays a major role in orchestrating the interaction between coagulation and inflammation. ${ }^{54}$ The PAR- 1 is a tethered ligand receptor that is activated by proteolytic cleavage of its extracellular domain. ${ }^{55}$ Activating proteases include thrombin, trypsin, factor $\mathrm{Xa}$, factor $\mathrm{XIla/X}$, and MMP-1. ${ }^{33}$ Although overexpression of PAR- 1 in the preeclamptic placenta has been previously demonstrated, ${ }^{35}$ we show herein, for the first time to our knowledge, that PAR-1 expression is increased in the vasculature of women with preeclampsia. Because PAR-1 is mostly confined to the endothelium in healthy human arteries, whereas during an inflammatory process, its expression is enhanced in regions associated with leukocyte influx, ${ }^{57}$ it is logical to infer that the increase in vascular PAR-1 during preeclampsia is mediated by infiltrating neutrophils. Contact between infiltrating neutrophils and VSMCs could induce overexpression of PAR-1, which then may be activated by the MMP-1 present in the microenvironment, triggering a cascade of downstream events that result in vascular dysfunction in women with preeclampsia.

The role of MMPs in vascular function includes regulation of vasoconstriction. ${ }^{19,20,58}$ Our data demonstrate that active MMP-1 is also a regulator of vascular reactivity. Therefore, increasing levels of MMP-1 in preeclampsia seem to be central to the hypertensive disorder observed in these women. We provide evidence that the vasoconstrictor effect of MMP-1 is mediated via PAR-1 because an antagonist of the receptor completely inhibits the vessel diameter reduction induced by activated MMP-1. Therefore, vascular reactivity would be enhanced because of increased expression of both MMP-1 and PAR-1 in those with preeclampsia. A previous report ${ }^{59}$ that describes that activation of PAR- 1 on vascular smooth muscle results in vasoconstriction supports our results.

As demonstrated herein, extracellular matrix remodeling has critical effects on vascular function and the con- 
sequent behavior of cells residing on or within it. ${ }^{17,18}$ In light of our findings, we propose that successive molecular events involving vascular neutrophil recruitment and secretion of MMP- 1 by VSMCs are implicated in the vascular dysfunction observed in preeclamptic women.

\section{References}

1. LaMarca BD, Ryan MJ, Gilbert JS, Murphy SR, Granger JP: Inflammatory cytokines in the pathophysiology of hypertension during preeclampsia. Curr Hypertens Rep 2007, 9:480-485

2. VanWijk MJ, Kublickiene K, Boer K, VanBavel E: Vascular function in preeclampsia. Cardiovasc Res 2000, 47:38-48

3. Flamant M, Placier S, Dubroca C, Esposito B, Lopes I, Chatziantoniou C, Tedgui A, Dussaule JC, Lehoux S: Role of matrix metalloproteinases in early hypertensive vascular remodeling. Hypertension 2007, 50:212-218

4. Lehoux S, Lemarie CA, Esposito B, Lijnen HR, Tedgui A: Pressureinduced matrix metalloproteinase-9 contributes to early hypertensive remodeling. Circulation 2004, 109:1041-1047

5. Lehoux S, Castier Y, Tedgui A: Molecular mechanisms of the vascular responses to haemodynamic forces. J Intern Med 2006, 259:381-392

6. Leik CE, Walsh SW: Neutrophils infiltrate resistance-sized vessels of subcutaneous fat in women with preeclampsia. Hypertension 2004, 44:72-77

7. Shah TJ, Walsh SW: Activation of NF-kappaB and expression of COX-2 in association with neutrophil infiltration in systemic vascular tissue of women with preeclampsia. Am J Obstet Gynecol 2007, 196:48.e1-48.e8

8. Cadden KA, Walsh SW: Neutrophils, but not lymphocytes or monocytes, infiltrate maternal systemic vasculature in women with preeclampsia. Hypertens Pregnancy 2008, 27:396-405

9. Walsh SW: Maternal-placental interactions of oxidative stress and antioxidants in preeclampsia. Semin Reprod Endocrinol 1998, 16:93104

10. Walsh SW, Vaughan JE, Wang Y, Roberts LJ 2nd: Placental isoprostane is significantly increased in preeclampsia. FASEB J 2000, 14: 1289-1296

11. Smith JA: Neutrophils, host defense, and inflammation: a doubleedged sword. J Leukoc Biol 1994, 56:672-686

12. Walsh SW: Obesity: a risk factor for preeclampsia. Trends Endocrinol Metab 2007, 18:365-370

13. Taniyama Y, Griendling KK: Reactive oxygen species in the vasculature: molecular and cellular mechanisms. Hypertension 2003, 42:1075-1081

14. Arenas IA, Xu Y, Lopez-Jaramillo P, Davidge ST: Angiotensin IIinduced MMP-2 release from endothelial cells is mediated by TNFalpha. Am J Physiol Cell Physiol 2004, 286:C779-C784

15. Moon SK, Cha BY, Kim CH: ERK1/2 mediates TNF-alpha-induced matrix metalloproteinase-9 expression in human vascular smooth muscle cells via the regulation of NF-kappaB and AP-1: involvement of the ras dependent pathway. J Cell Physiol 2004, 198:417-427

16. Lee SJ, Seo KW, Yun MR, Bae SS, Lee WS, Hong KW, Kim CD: 4-Hydroxynonenal enhances MMP-2 production in vascular smooth muscle cells via mitochondrial ROS-mediated activation of the Akt/ NF-kappaB signaling pathways. Free Radic Biol Med 2008, 45:14871492

17. Streuli C: Extracellular matrix remodelling and cellular differentiation. Curr Opin Cell Biol 1999, 11:634-640

18. Shapiro SD: Matrix metalloproteinase degradation of extracellular matrix: biological consequences. Curr Opin Cell Biol 1998, 10:602608

19. Fernandez-Patron C, Radomski MW, Davidge ST: Vascular matrix metalloproteinase-2 cleaves big endothelin-1 yielding a novel vasoconstrictor. Circ Res 1999, 85:906-911

20. Fernandez-Patron C, Stewart KG, Zhang Y, Koivunen E, Radomski MW, Davidge ST: Vascular matrix metalloproteinase-2-dependent cleavage of calcitonin gene-related peptide promotes vasoconstriction. Circ Res 2000, 87:670-676

21. Sankaralingam S, Arenas IA, Lalu MM, Davidge ST: Preeclampsia: current understanding of the molecular basis of vascular dysfunction. Expert Rev Mol Med 2006, 8:1-20
22. Mellembakken JR, Aukrust $P$, Olafsen MK, Ueland T, Hestdal $K$ Videm V: Activation of leukocytes during the uteroplacental passage in preeclampsia. Hypertension 2002, 39:155-160

23. Saito S, Sakai M: Th1/Th2 balance in preeclampsia. J Reprod Immunol 2003, 59:161-173

24. Leik CE, Willey A, Graham MF, Walsh SW: Isolation and culture of arterial smooth muscle cells from human placenta. Hypertension 2004, 43:837-840

25. Forman HJ, Maiorino M, Ursini F: Signaling functions of reactive oxygen species. Biochemistry 2010, 49:835-842

26. Vaughan JE, Walsh SW, Ford GD: Thromboxane mediates neutrophil superoxide production in pregnancy. Am J Obstet Gynecol 2006, 195:1415-1420

27. Rosenfeldt MT, Valentino M, Labruzzo S, Scudder L, Pavlaki M, Cao J, Vacirca J, Bahou WF, Zucker S: The organomercurial 4-aminophenylmercuric acetate, independent of matrix metalloproteinases, induces dose-dependent activation/inhibition of platelet aggregation. Thromb Haemost 2005, 93:326-330

28. Gomez-Lopez N, Estrada-Gutierrez G, Jimenez-Zamudio L, VegaSanchez R, Vadillo-Ortega F: Fetal membranes exhibit selective leukocyte chemotaxic activity during human labor. J Reprod Immunol 2009, 80:122-131

29. Grab DJ, Nyarko E, Barat NC, Nikolskaia OV, Dumler JS: Anaplasma phagocytophilum-Borrelia burgdorferi coinfection enhances chemokine, cytokine, and matrix metalloprotease expression by human brain microvascular endothelial cells. Clin Vaccine Immunol 2007. 14:1420-1424

30. Sassi ML, Eriksen H, Risteli L, Niemi S, Mansell J, Gowen M, Risteli J: Immunochemical characterization of assay for carboxyterminal telopeptide of human type I collagen: loss of antigenicity by treatment with cathepsin K. Bone 2000, 26:367-373

31. Gaggar A, Jackson PL, Noerager BD, O'Reilly PJ, McQuaid DB Rowe SM, Clancy JP, Blalock JE: A novel proteolytic cascade generates an extracellular matrix-derived chemoattractant in chronic neutrophilic inflammation. J Immunol 2008, 180:5662-5669

32. Riley DJ, Berg RA, Soltys RA, Kerr JS, Guss HN, Curran SF, Laskin $\mathrm{DL}$ : Neutrophil response following intratracheal instillation of collagen peptides into rat lungs. Exp Lung Res 1988, 14:549-563

33. Boire A, Covic L, Agarwal A, Jacques S, Sherifi S, Kuliopulos A: PAR1 is a matrix metalloprotease- 1 receptor that promotes invasion and tumorigenesis of breast cancer cells. Cell 2005, 120:303-313

34. Leger AJ, Covic L, Kuliopulos A: Protease-activated receptors in cardiovascular diseases. Circulation 2006, 114:1070-1077

35. Erez O, Romero R, Kim SS, Kim JS, Kim YM, Wildman DE, Than NG, Mazaki-Tovi S, Gotsch F, Pineles B, Kusanovic JP, Espinoza J, Mittal P. Mazor M, Hassan SS, Kim CJ: Over-expression of the thrombin receptor (PAR-1) in the placenta in preeclampsia: a mechanism for the intersection of coagulation and inflammation. J Matern Fetal Neonatal Med 2008, 21:345-355

36. Martinez A, Oh HR, Unsworth EJ, Bregonzio C, Saavedra JM, StetlerStevenson WG, Cuttitta F: Matrix metalloproteinase-2 cleavage of adrenomedullin produces a vasoconstrictor out of a vasodilator. Biochem J 2004, 383:413-418

37. Ku DD, Dai J: Expression of thrombin receptors in human atherosclerotic coronary arteries leads to an exaggerated vasoconstrictory response in vitro. J Cardiovasc Pharmacol 1997, 30:649-657

38. Cicala C, Morello S, Santagada V, Caliendo G, Sorrentino L, Cirino G: Pharmacological dissection of vascular effects caused by activation of protease-activated receptors 1 and 2 in anesthetized rats. FASEB J 2001, 15:1433-1435

39. Strande JL, Hsu A, Su J, Fu X, Gross GJ, Baker JE: SCH 79797, a selective PAR1 antagonist, limits myocardial ischemia/reperfusion injury in rat hearts. Basic Res Cardiol 2007, 102:350-358

40. Bankowski E, Romanowicz L, Jaworski S: Collagen of umbilical cord arteries and its alterations in EPH-gestosis. J Perinat Med 1993, $21: 491-498$

41. Baumwell S, Karumanchi SA: Pre-eclampsia: clinical manifestations and molecular mechanisms. Nephron Clin Pract 2007, 106:c72-c81

42. Hladunewich M, Karumanchi SA, Lafayette R: Pathophysiology of the clinical manifestations of preeclampsia. Clin J Am Soc Nephrol 2007, 2:543-549

43. Greer IA, Haddad NG, Dawes J, Johnstone FD, Calder AA: Neutrophil activation in pregnancy-induced hypertension. $\mathrm{Br} J$ Obstet Gynaecol 1989, 96:978-982 
44. Gervasi MT, Chaiworapongsa T, Pacora P, Naccasha N, Yoon BH, Maymon E, Romero R: Phenotypic and metabolic characteristics of monocytes and granulocytes in preeclampsia. Am J Obstet Gynecol 2001, 185:792-797

45. Lee VM, Quinn PA, Jennings SC, Ng LL: Neutrophil activation and production of reactive oxygen species in pre-eclampsia. J Hypertens 2003, 21:395-402

46. Mellembakken JR, Aukrust P, Hestdal K, Ueland T, Abyholm T, Videm $\mathrm{V}$ : Chemokines and leukocyte activation in the fetal circulation during preeclampsia. Hypertension 2001, 38:394-398

47. Zhu Y, Hojo Y, Ikeda U, Takahashi M, Shimada K: Interaction between monocytes and vascular smooth muscle cells enhances matrix metalloproteinase-1 production. J Cardiovasc Pharmacol 2000, 36:152161

48. Vaughan JE, Walsh SW: Neutrophils from pregnant women produce thromboxane and tumor necrosis factor-alpha in response to linoleic acid and oxidative stress. Am J Obstet Gynecol 2005, 193:830-835

49. Rajagopalan S, Meng XP, Ramasamy S, Harrison DG, Galis ZS: Reactive oxygen species produced by macrophage-derived foam cells regulate the activity of vascular matrix metalloproteinases in vitro: implications for atherosclerotic plaque stability. J Clin Invest 1996, 98:2572-2579

50. Walsh SW: Plasma from preeclamptic women stimulates transendothelial migration of neutrophils. Reprod Sci 2009, 16:320-325

51. Schonbeck U, Brandt E, Petersen F, Flad HD, Loppnow H: IL-8 specifically binds to endothelial but not to smooth muscle cells. $\mathrm{J}$ Immunol 1995, 154:2375-2383
52. Faveeuw C, Preece G, Ager A: Transendothelial migration of lymphocytes across high endothelial venules into lymph nodes is affected by metalloproteinases. Blood 2001, 98:688-695

53. Van Lint P, Libert C: Chemokine and cytokine processing by matrix metalloproteinases and its effect on leukocyte migration and inflammation. J Leukoc Biol 2007, 82:1375-1381

54. Melnikova VO, Balasubramanian K, Villares GJ, Dobroff AS, Zigler M Wang $\mathrm{H}$, Petersson F, Price JE, Schroit A, Prieto VG, Hung MC, Bar-Eli M: Crosstalk between protease-activated receptor 1 and plateletactivating factor receptor regulates melanoma cell adhesion molecule (MCAM/MUC18) expression and melanoma metastasis. J Biol Chem 2009, 284:28845-28855

55. Coughlin SR: Thrombin signalling and protease-activated receptors Nature 2000, 407:258-264

56. Derian CK, Maryanoff BE, Zhang HC, Andrade-Gordon P: Therapeutic potential of protease-activated receptor-1 antagonists. Expert Opin Investig Drugs 2003, 12:209-221

57. Nelken NA, Soifer SJ, O'Keefe J, Vu TK, Charo IF, Coughlin SR: Thrombin receptor expression in normal and atherosclerotic human arteries. J Clin Invest 1992, 90:1614-1621

58. Merchant SJ, Davidge ST: The role of matrix metalloproteinases in vascular function: implications for normal pregnancy and preeclampsia. Bjog 2004, 111:931-939

59. Magazine HI, Butt O, Yaghoutiel HR: Endothelin and nitric oxide release modulate aortic contraction to selected thrombin receptor agonists. Am J Physiol 1996, 270:C1815-C1818 